\title{
CORRELATION OF SKELETAL MATURATION STAGES OF MP3 WITH ONSET OF MENARCHE AMONGST RURAL AND URBAN SCHOOL GIRLS
}

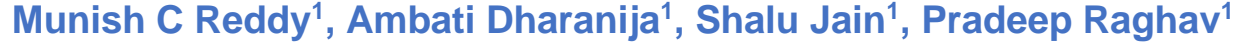 \\ 1. Department of Orthodontics and Dentofacial Orthopaedics, Swami Vivekanand Subharti University, \\ Meerut (U.P.), India.
}

\begin{abstract}
Introduction: The purpose of this study was to evaluate and correlate skeletal maturation stages of Middle phalanx of third finger (MP3) with the onset of menarche in rural and urban school girls.

Materials and methods: 100 urban school girls and 100 rural school girls were randomly selected comprising of 50 menarche unattained girls and 50 menarche attained girls respectively for each group. For each subject, radiographs of middle phalanx of middle finger and record about onset of menarche were taken after every three months for a total duration of one and half year comprising a total of 6 visits.

Results: The results showed onset of menarche at HI MP3 stage for $50 \%$, HMP3 stage for $47.5 \%$ and GMP3 stage for $2.5 \%$ in rural girls (subgroup D2) whereas onset of menarche was at HMP3 stage for $41.6 \%$, HI MP3 stage for 50\% and GMP3 stage for $8.33 \%$ in urban girls (subgroup B2). No significant difference in the MP3 skeletal stage distribution of two groups was seen after applying Chi-square test $(P>0.05)$. The mean menarche attaining age of the rural girls was $12.6 \pm .84$ years and urban girls was $11.8 \pm .79$ years.

Conclusions: The correlation between MP3 skeletal maturation and onset of menarche, established the onset of menarche at $\mathrm{H}$ and $\mathrm{HI}$ stage for both rural and urban school girls. The results show earlier mean menarche-attaining age for urban girls than rural girls.
\end{abstract}

Keywords: Middle phalanx third finger (MP3), Menarche, Peak height velocity, Skeletal maturity indicators, Growth

Address for Correspondence:

Dr.Ambati .Dharanija, Junior Resident, Department of orthodontics and dentofacial orthopaedics, Swami Vivekanand

Subharti University, Meerut (UP), INDIA,250002

Date of Receiving: 04 August 2020

Date of Acceptance: 27 August 2020

0970-1842/Copyright (C) JAS 2020 


\section{INTRODUCTION}

Skeletal maturation is the metamorphosis of the cartilaginous and membranous bones of the foetus to the fully ossified bones of the adult [1] or can be defined as the degree of development of ossification in bone [16]. As a person grows from foetal life through child hood, puberty and finishes growth as a young adult, the part of bone, the epiphysis changes in size and shape. There is initial appearance of epiphysis and subsequent ossification of epiphyseal cartilage and finally its fusion which can be appreciated in the radiographs. These sequences of changes in bone is consistent for every individual since everyone has his own biologic clock.

The introduction of radiography by Roentgen was of great utility in various fields. Hand and wrist radiographs for skeletal maturation assessment were first utilized by Greulich and Pyle [17] followed by Grave and Brown [13], Fishman [11] and Hagg and Taranger [15]. Similarly, lateral cephalograms for skeletal maturation assessment were first utilized by Lamparski [26] followed by Hassel and Farman [16] and Baccettie et al. [5]. Skeletal maturation assessment with the middle phalanx of the third finger (MP3) was studied by Hagg and Taranger [15] which was later modified by Rajgopal and Kansal [27]. They described the various stages of development of the middle phalanx of the third finger as FMP3, FGMP3, GMP3, HMP3, HIMP3 and IMP3 (Fig. 1) and concluded that it is a simple, accurate, easy to interpret, practical and economical method with minimal radiation exposure for making a decision on treatment timing when compared to Cervical Vertebrae Maturation Index staging.

Menarche is a distinct benchmark for sexual maturation. The age at menarche, an easily recallable event, is an important biologic indicator in assessing the physiologic maturity in girls. The relationship between the growth spurt in body height and onset of menarche has been investigated $[25,28]$. It has been seen that the peak height velocity is attained a year before menarche [8] and so, it occurs after the initiation of the adolescent growth spurt. It is known to be influenced by genetics, ethnic origins, socioeconomic status, general living conditions, and environmental factors [19].

The identification of skeletal maturation levels and its correlation with onset of menarche provides a very useful means of identifying specific periods along the path of adolescent growth that provides a new dimension for evaluating general and individual growth including facial growth with the help of middle phalanx of third finger (MP3) radiographs. This identification of peak growth period helps in treating orthopaedic problems such as mandibular retrognathism effectively by myofunctional appliance therapy. These are designed to alter the position of mandible both sagittally \& vertically inducing lengthening of the mandible and stimulating increased growth at the condylar cartilage. Hence the aim of this study is to evaluate and correlate skeletal maturation stages of MP3 (Middle phalanx of third finger) with the onset of menarche in rural and urban school girls. 


\section{MATERIALS AND METHODS}

This was a prospective longitudinal study consisting of 200 girls randomly divided into 100 urban school girls (Group I) and 100 rural school girls (Group II). 100 urban girls (Group I) further consisted of 50 menarche unattained girls (Sub group B) and 50 menarche attained girls (Sub group A). Out of 50 menarche unattained urban girls (Sub group B) 25 remained unattained (Subgroup B1), 24 had attained menarche (Subgroup B2) and there was 1 drop out. Similarly, 100 rural girls (Group II) further consisted of 50 menarche unattained girls (Sub group D) and 50 menarche attained girls (Sub group C) Out of 50 menarche unattained rural girls (Sub group D) 10 remained unattained (Subgroup D1) and 40 had attained menarche (Subgroup D2). The age group of the sample was taken from 10 years to 14 years. A written consent from the parents of school children was taken for taking third finger Xray for the study.

For each subject, radiographs of middle phalanx of middle finger and record about onset of menarche were taken after every three months and were taken for total duration of one and half year comprising total of 6 visits. For taking X-ray, armamentarium used for the study was Portable $\mathrm{X}$ ray machine (Genoray portable X-ray system Power output: 180W, Tube Voltage: $60 \mathrm{KV}$, Tube Current: $2 \mathrm{~mA}$, Focal Spot: 0.8mm, Exposure time set: 0.1-2.0 sec, Power requirement: 22VDC), RVG (Digital Radiovisiography, Kodak RVG 5100 system resolution: $14 \mathrm{lp} / \mathrm{mm}$.) and customized portable $\mathrm{X}$ ray box.
For taking X-ray, the RVG sensor was placed over the finger and sensor stabilizing unit in the $X$ ray box. Then the moving glass slide was placed over the sensor and individual was asked to pass her hand inside the portable Xray box keeping their third finger on glass slide which was placed over the stand. Then this was exposed to $\mathrm{X}$-rays by passing the X-ray tube above it. The MP3 Xrays were evaluated and staged according to the system given by Rajgopal and Kansal [27] (Fig. 1). Our study showed that Spearman's rank correlation of interobserver reliability ranged from 0.997 to 0.999 for the MP3 staging system. The correlation for intraobserver reliability was 1.000 and all correlations were found to be statistically significant.

Descriptive statistics were used to calculate the means and standard deviations of the chronological age of onset of menarche. Unpaired $\mathrm{T}$ test for comparison of mean menarche attaining age and for comparison of MP3 stages at onset of menarche between rural and urban girls were carried out.



Fig. 1. Skeletal developmental stages of the middle phalanx of the third finger. 


\section{RESULTS}

The mean age of the girls in our study was $12.19 \pm 1.01$ years. The mean age of the rural girls (Group I) was $12.24 \pm 1.04$ years and urban girls (Group II) was $12.15 \pm 1$ years (Table 1 \& Fig. 2). The mean menarche attaining age of the rural girls was $12.6 \pm .84$

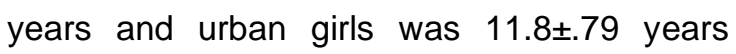
(Table 2 \& Fig. 3).

The age of attaining menarche was higher in rural girls (subgroup D2) as compared to urban girls (subgroup B2) and the difference was statistically significant $(P<.01)$ as shown in (Table 2 and Fig. 3).

When comparing the menarche attaining age at various modified skeletal MP3 maturation stages for rural and urban group i.e. subgroup $\mathrm{D} 2$ and B2, it showed onset of menarche at $\mathrm{HI}$ MP3 stage for $50 \%$, HMP3 stage for $47.5 \%$ and GMP3 stage for $2.5 \%$ in rural girls (subgroup D2) whereas onset of menarche was at HMP3 stage for $41.6 \%$, HIMP3 stage for $50 \%$ and GMP3 stage for $8.33 \%$ in urban girls (subgroup B2).

No significant difference in the MP3 skeletal stage distribution of two groups was seen after applying Chi-square test $(P>0.05)$. (Table 3 and Fig. 4).

The urban and rural girls who had already attained menarche (subgroup $C$ and $D$ ) showed $\mathrm{HI}$ and I MP3 stages and unattained menarche girls (subgroup B1 \& D1) showed FG MP3 and G MP3 stage.

\section{DISCUSSION}

The knowledge of growth, its effect on development of dentofacial complex in particular and the body in general leads to early prevention and interception of dentofacial deformities. This further depends upon accurate interpretation of the inherent facioskeletal pattern and overall growth and development.

Since several studies $[2,6,27,22,18]$ showed high correlation of MP3 developmental stages when compared with CVMI stages or handwrist assessment or with dental maturity indicators, so MP3 stages can be used as sole indicator for skeletal maturation assessment of an individual. MP3 radiograph show high degree of clarity, with no superimposition of bones or variations in posture as in evaluation of the cervical vertebrae. They show discrete, easily identifiable stages of development, unlike the more subtle changes in CVMI stages as described by Raj Gopal Kansal [27]. They show good reliability and reproducibility [27]. CVMI methods requires elaborate equipment and the radiation exposure time and dose are also high. Digital radiography was used instead of using conventional film in the present study since Abdel-Kader 1998 [3] concluded that digitized radiographic images of the MP3 have five times less exposure than conventional approach. These digital images also increase the scope for cross-sectional and longitudinal studies.

The age of attainment of menarche is influenced by various factors such as Socioeconomic status, diet, nutrition, genetic factors 
and physical activity [19]. The mean menarche attaining age for rural girls was $12.60 \pm .84$ years (subgroup D2) and 11.8土.79 years for urban girls (subgroup B2) showing statistically significant difference. The mean rural menarche attaining age (12.04 \pm 0.89 years) was in accordance with study done by Banerjee I et al (2007) [4], Khatoon (2011) [19], Khadgawat et al (2016) [20] and Pandey M and Pradhan A (2017) [23] in which the mean age at menarche was 12.3 years, $12.43 \pm 1.49$ years, 12.4 years and 12.52 years respectively. Whereas the present results are contrary to the study of Pathak et al [24].

This reduction of menarche attaining age in our study was due to improvement in the field of scientific and technological advancement, economic growth, agriculture, food supply, public health systems and hygiene, which markedly help to improve the general health, nutritional level and over all standard of living of the population when compared to past several decades.

The results show earlier mean menarche attaining age for urban girls (subgroup B2 $11.8 \pm .79$ years) than mean menarche attaining age for rural girls of $(12.60 \pm .84$ years in subgroup D2) showing statistically significant difference. This is in accordance with the study of Chidiebere et al [9] and Khatoon et al [19]. Since rural girls do more physical activity, have low socioeconomic status and are less nourished hence show less fat accumulation. Thus, there is release of androgen hormones (aldosterone) which delays menarche.
When comparison was done for menarche attaining age at various modified skeletal MP3 maturation stages given by Rajagopal and Kansal [27] for rural and urban group i.e. subgroup D2 and B2. It was seen that menarche was attained in HI MP3 stage for $50 \%$, HMP3 stage for $47.5 \%$ and GMP3 stage for $2.5 \%$ in rural girls (subgroup D2) whereas menarche was attained in HMP3 stage for $41.6 \%$, HIMP3 stage for $50 \%$ and GMP3 stage for $8.33 \%$ in urban girls (subgroupB2). The increased per cent of earlier skeletal MP3 stage in urban girl (sub group B2) compared to rural girl (sub group D2) attributed to earlier menarche attaining age in urban girls compared to rural girls. According to Rajagopal and Kansal [27] modified 6 MP3 stage can be compared to $6 \mathrm{CVMI}$ stages. Therefore, our results are in accordance to the study of Moradinejad et al where highest incidence rates of menarche were noted in the fourth and fifth stages of the development of cervical vertebrae.

The results are in contradictory to the study of Vichare et in which Menarche occurred during SMI 7-8 and CVM Stage III-IV which may be due to overall poor reproducibility of the CVM method according to Gabriel et al [14], Baptista et al [7] and Nestman et al [21]. So there is variation in staging done from MP3 stage.

\section{CONCLUSION}

Several studies $[10,12,29]$ support the hypothesis that the peak height velocity is attained one year before menarche and then it 


\begin{tabular}{|l|l|l|l|l|}
\hline \multirow{2}{*}{$\begin{array}{l}\text { Age } \\
\text { in years) }\end{array}$} & \multicolumn{2}{|c|}{ Group } & \multirow{2}{*}{ Total (n=124) } & \multirow{2}{*}{ P value } \\
\cline { 2 - 4 } & Rural(n=94) & Urban(n=94) & & \\
\hline $\mathbf{1 0 - 1 1}$ years & $16(17.0 \%)$ & $13(13.8 \%)$ & $29(15.5 \%)$ & \\
$\mathbf{1 1 - 1 2}$ years & $16(17.0 \%)$ & $24(25.5 \%)$ & $40(21.3 \%)$ & \\
$\mathbf{1 2 - 1 3}$ years & $38(40.5 \%)$ & $31(32.9 \%)$ & $69(36.7 \%)$ & \multirow{2}{*}{0.615} \\
>13 years & $24(25.5 \%)$ & $26(27.6 \%)$ & $50(26.5 \%)$ & \\
Total & $94(100.00 \%)$ & $94(100.00 \%)$ & $188(100.00 \%)$ & \\
\hline Mean $\mathbf{n}$ Stdev & $12.24 \pm 1.04$ & $12.15 \pm 1$ & $12.19 \pm 1.01$ & \\
\hline Median & 12.49 & 12.38 & 12.43 & 0.787 \\
$($ IQR) & $(11.519-13.014)$ & $(11.253-13.116)$ & $(11.352-13.036)$ & \\
\hline
\end{tabular}

Table 1. Comparison of age distribution between rural (Group I) and urban (Group II) girls

\section{Comparison of age between rural and urban girls}

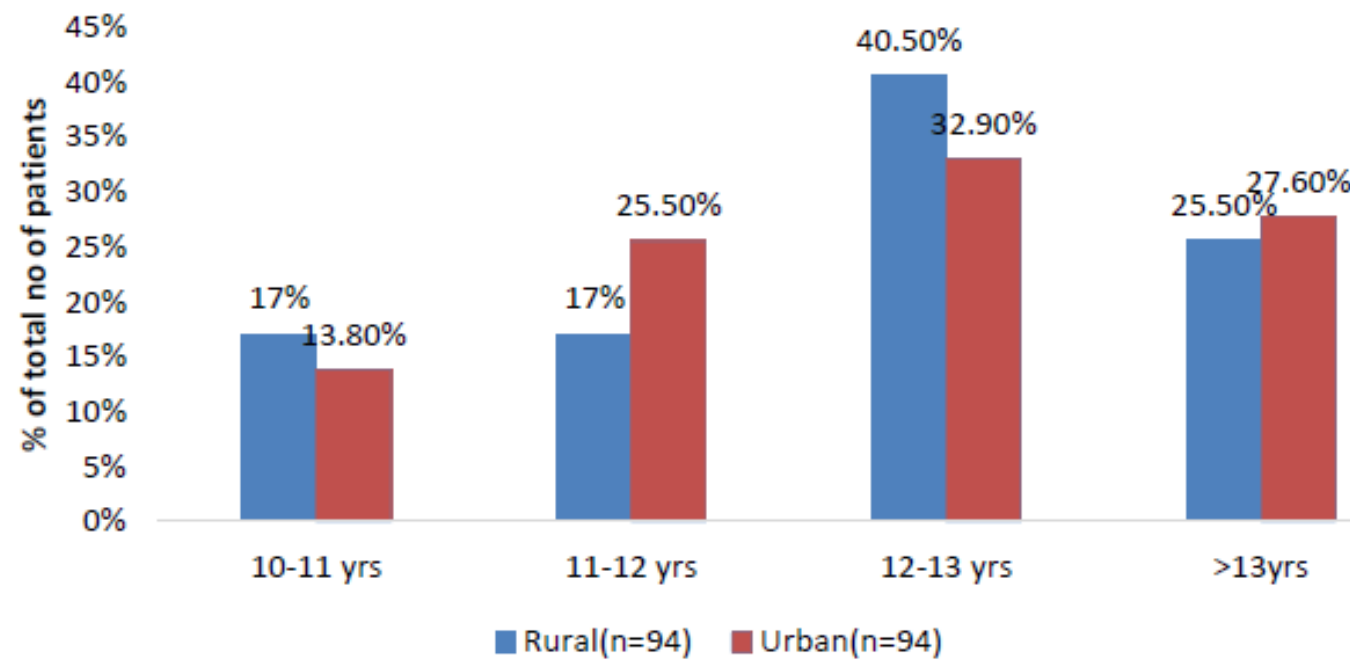

Fig. 2. Comparison of age distribution between rural (Group I) and urban (Group II) girls 


\begin{tabular}{|c|c|c|c|c|c|}
\hline \multirow{3}{*}{$\begin{array}{l}\text { Menarche attainin } \\
\mathrm{g} \text { age in years }\end{array}$} & \multicolumn{2}{|c|}{ Rural $(n=40)$} & \multicolumn{2}{|c|}{ Urban $(n=24)$} & \multirow{2}{*}{$\begin{array}{l}P \\
\text { value }\end{array}$} \\
\hline & $\begin{array}{l}\text { Mean } \pm \\
\text { Stdev }\end{array}$ & Median (IQR) & $\begin{array}{ll}\text { Mean } & \pm \\
\text { Stdev } & \end{array}$ & Median (IQR) & \\
\hline & $\begin{array}{l}12.60 \pm \\
0.85\end{array}$ & $\begin{array}{l}12.50(12.2291 \\
3.104)\end{array}$ & $\begin{array}{ll}11.91 \quad \pm \\
0.79\end{array}$ & $\begin{array}{l}11.87(11.167-1 \\
2.458)\end{array}$ & 0.002 \\
\hline
\end{tabular}

Table 2. Comparison of menarche attaining age between rural and urban girls (subgroup B2 \& subgroup D2)

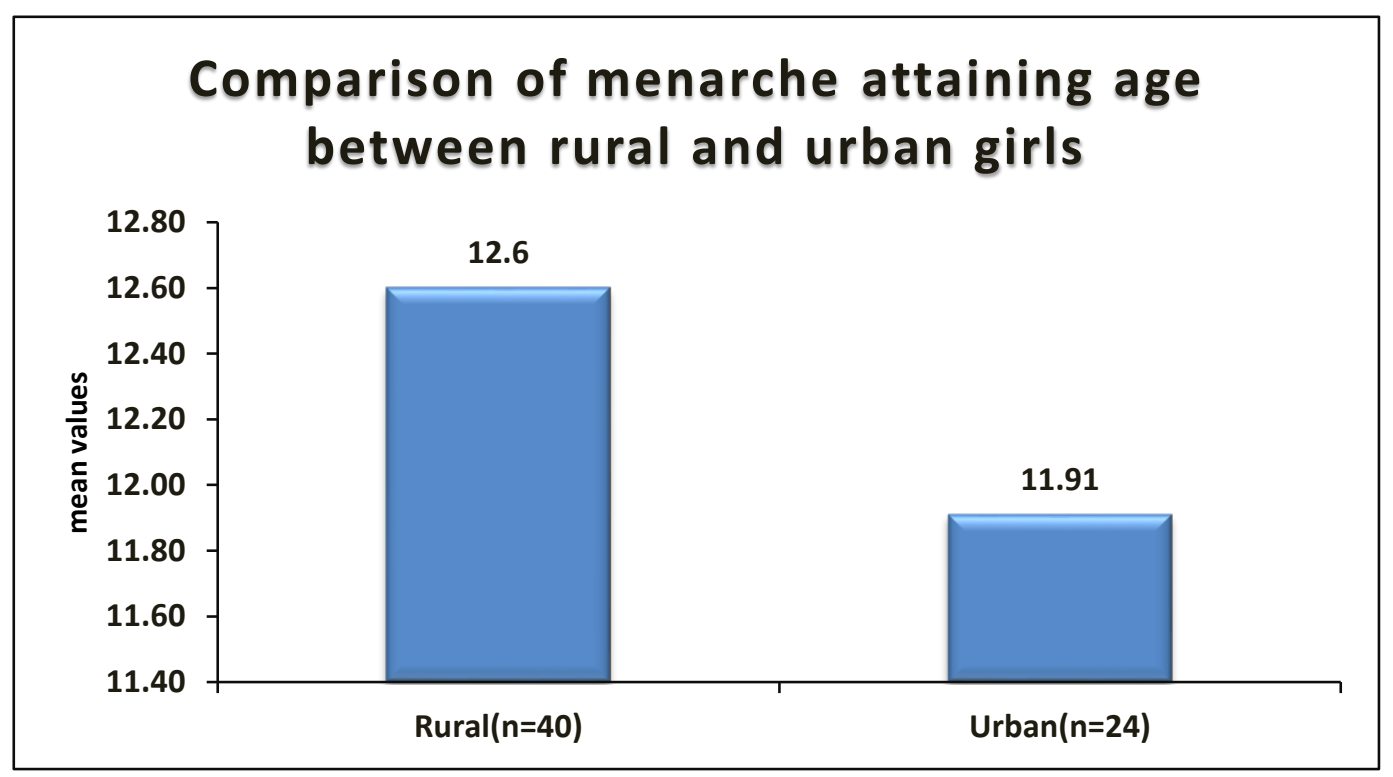

Fig. 3. Comparison of menarche attaining age between rural and urban girls (subgroup B2 \& subgroup D2)

\begin{tabular}{|c|r|r|r|c|}
\hline \multirow{2}{*}{ MP3 Stages } & \multicolumn{2}{|c|}{ Group } & \multirow{2}{*}{} & \multirow{2}{*}{} \\
\cline { 2 - 4 } & & \multicolumn{1}{|c|}{ Total } & P value \\
\cline { 2 - 4 } G MP3 & $1(2.5 \%)$ & $2(8.33 \%)$ & $3(4.69 \%)$ & \\
H MP3 & $19(47.5 \%)$ & $12(50.00 \%)$ & $31(48.44 \%)$ & \multirow{2}{*}{0.514} \\
HI MP3 & $20(50.00 \%)$ & $10(41.67 \%)$ & $30(46.87 \%)$ & \\
Total & $40(100.00 \%)$ & $24(100.00 \%)$ & $64(100.00 \%)$ & \\
\hline
\end{tabular}

Table 3. Comparison of MP3 Stages at onset of menarche between rural and urban girls (subgroup D2 \& B2) 


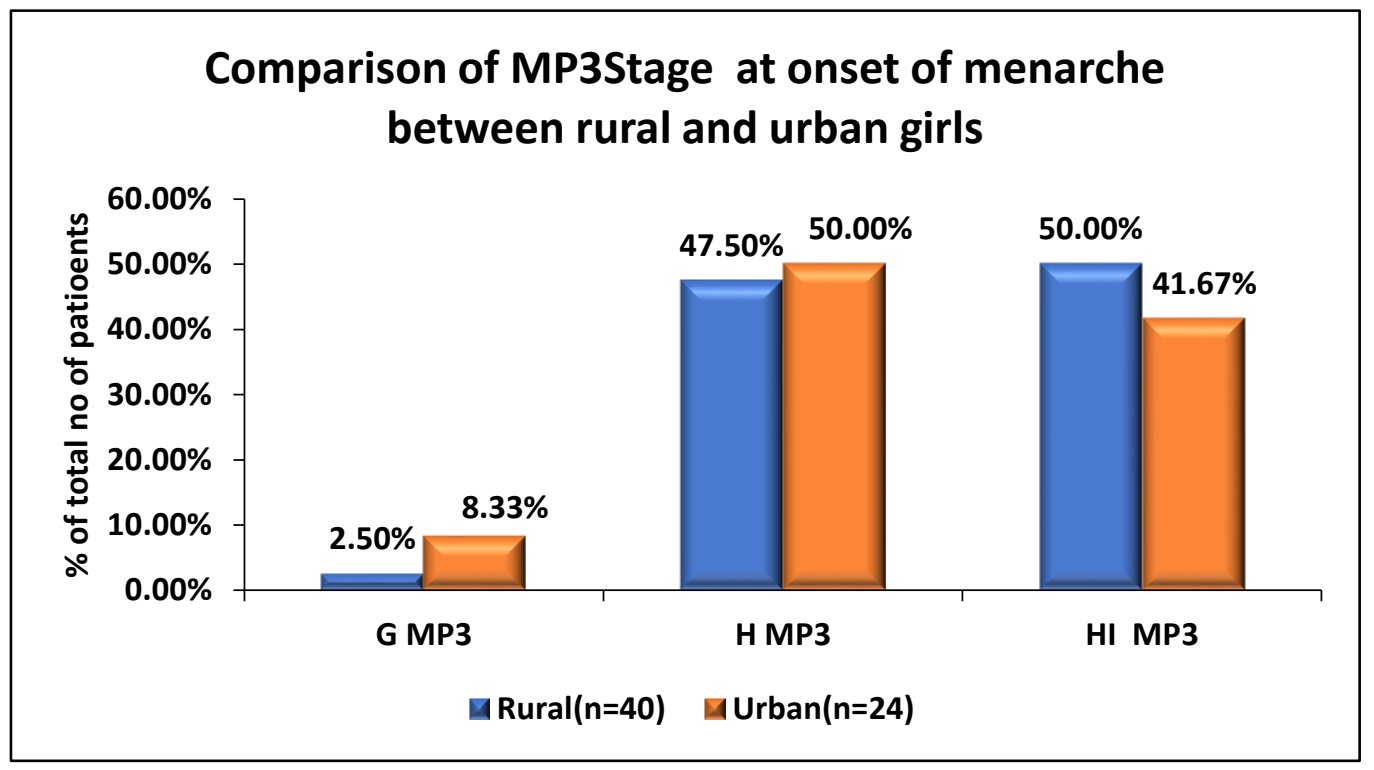

Fig. 4. Comparison of MP3 Stages at onset of menarche between rural and urban girls (subgroup D2 \&B2)

slows down thereafter and stops within 1 year after menarche because of the closing of epiphyses of long bones. In our study the correlation between MP3 skeletal maturation and onset of menarche showed onset of menarche at $\mathrm{H}$ and $\mathrm{HI}$ stage, So this helps in timing the functional appliance which are most effect when given at mandible's maximum growth potential and after onset of menarche. After HI MP3 stage, the treatment planning moves towards orthognathic surgeries. Hence correlation of skeletal MP3 stages with onset of menarche helps in identifying growth status of a person by diagnosing MP3 radiographs which further helps in deciding various treatment modalities.

\section{REFERENCES}

1. Acheson RM (1954) A method of assessing skeletal maturity from radiographs: a report from the Oxford Child Health Survey. J Anat 88: 498-508.
2. A Tikku T, Khanna R, Sachan K, Agrawal S. Correlation of improved version of cervical vertebral maturation indicator with other growth maturity indicators. J Indian Orthod Soc. 2013;47(1):28-32. Cad Forensic Med. 2011;33(5):971-3.

3. Abdel-Kader HM. The potential of digital dental radiography in recording the adductor sesamoid and the MP3 stages. J Orthod. 1999;26(4):291-4.

4. Banerjee I, Chakraborty S, Bhattacharya NG, Bandopadhyay S, Saiyed HN, Mukherjee D. A cohort study of correlation between body mass index and age at menarche in healthy Bengali girls. J Indian Med Assoc. 2007;105(2):75-8.

5. Baccetti T, Franchi L, McNamara Jr JA. The cervical vertebral maturation (CVM) method for the assessment of optimal treatment timing in dentofacial orthopedics. Semin Orthod. 2005;11(3):119-29.

6. Bala M, Pathak A, Jain RL. Assessment of skeletal age using MP 3 and hand-wrist radiographs and its correlation with dental and chronological ages in children. J Indian Soc Pedod Prev Dent. 2010;28(2):95-102. 
7. Baptista RS, Quaglio CL, Mourad LM, Hummel AD, Caetano CA, Ortolani CL, et al. A semi-automated method for bone age assessment using cervical vertebral maturation. Angle Orthod. 2012;82(4):658-62.

8. Chang SH, Tzeng SJ, Cheng JY, Chie WC. Height and weight change across menarche of schoolgirls with early menarche. Arch Pediatr Adolsc Med. 2000;154(9):880-4.

9. Chidiebere I, Ikaraoha M, Chidi I, Dennis A, Okoye M, Golden I et al. Menarchial Age of Secondary School Girls in Urban and Rural Areas of Rivers State, Nigeria. J Health Allied Scs. 2005;4(2):56-63.

10. Chang SH, Tzeng SJ, Cheng JY, Chie WC. Height and weight change across menarche of schoolgirls with early menarche. Arch Pediatr Adolsc Med. 2000;154(9):880-4.

11.Fishman LS. Radiographic evaluation of skeletal maturation: A clinically oriented method based on hand-wrist films. Angle Orthod. 1982;52(2):88-112.

12. Forbes GB. Body size and composition of premenarchal girls. Am J Dis Child. 1992;146(5):63-6.

13.Grave KC, Brown T. Skeletal ossification and the adolescent growth spurt. Am J Orthod. 1976;69(6):611-9.

14.Gabriel DB, Southard KA, Qian F, Marshall SD, Franciscus RG, Southard TE. Cervical vertebrae maturation method: Poor reproducibility. Am J Orthod Dentofacial Orthop. 2009;136(1):478-84.

15. Hagg U, Taranger J. Maturation indicators and the pubertal growth spurt. Am J Orthod. 1982;82(4):299-309.

16. Hassel B, Farman A. Skeletal maturation evaluation using cervical vertebrae. Am J Orthod Dentofacial Orthop. 1995;107(2):5866.

17.Iannaccone G, Greulich WW and Pyle SI: Radiographic atlas of skeletal development of the hand and wrist. Stanford University
Press, Stanford, California, 1959. Acta Genet Med Gemellol. 1959;8(4):513-8.

18.Joshi M, Rao D, Shubha AB, Panwar S, Franklin $\mathrm{S}$. A radiographic assessment of the correlation between the calcification stages of the mandibular second molar and the middle phalanx of the third finger of 916 years old children. Egypt J Forensic Sci. 2018;8(1):35.

19. Khatoon T, Verma AK, Kumari R, Rupani R, Singh M, Rizvi A. Age at menarche and affecting bio-social factors among the girls of Lucknow, Uttar Pradesh. J Indian Acad Forensic Med. 2011;33(5):971-3.

20.Khadgawat R, Marwaha RK, Mehan N, Surana V, Dabas A, Sreenivas V et al. Age of onset of puberty in apparently healthy school girls from Northern India. Indian Pediatr. 2016;53(5):383-7.

21.Nestman TS, Marshall SD, Qian F, Holton N, Franciscus RG, Southard TE. Cervical vertebrae maturation method morphologic criteria: Poor reproducibility. Am J Orthod Dentofacial Orthop. 2011;140(7):182-8.

22.Prasad M, Ganji VS, George SA, Talapaneni AK, Shetty SK. A comparison between cervical vertebrae and modified MP3 stages for the assessment of skeletal maturity. J Nat Sci Biol Med. 2013;4(1):747.

23.Pandey M, Pradhan A. Age of attainment of menarche and factors affecting it amongst school girls of Gangtok, Sikkim, India. Int J Contemp Pediatr. 2017;4(6):187-92.

24.Pathak PK, Tripathi N, Subramanian SV. Secular trends in menarcheal age in Indiaevidence from the Indian human development survey. Plos One. 2014;9(11):1-13.

25. Richey HG. The relation of accelerated, normal and retarded puberty to the height and weight of school children. Monographs of the Society for Research in Child Development. 1937;2(1):i-67. 
26. Roman PS, Palma JC, Oteo MD, Nevado E. Skeletal maturation determined by cervical vertebrae development. Eur J Orthod. 2002;24(3):303-11.

27.Rajgopal R, Kansal S. A Comparision of modified MP3 stages and the cervical vertebrae as a growth indicator. Am J Orthod Dentofacial Orthop. 2002;36(3):398406.

28. St George IM, Williams S, Silva PA. Body size and the menarche: the Dunedin study. J Adolesc Health. 1994;15(2):573-6.

29. Tanner JM, Davis PSW. Clinical longitudinal standards for height and height velocity for North American children. J Pediatr. 1985;107(3):317-29. 